\title{
The Resistance to Belief
}

\author{
Arthur Hastings, Ph.D. \\ Institute of Transpersonal Psychology, Palo Alto, CA
}

\begin{abstract}
William James's essay "The Will to Believe" proposed that we are sometimes justified, even obligated, to believe from our strong emotional or passional nature that something is true, even though there may not be total logical, evidential proof-which he also wrote is not to be found in this world. This essay explores situations, using a recent dear-death experience (NDE) example, in which there are reasonable evidence and logic, and yet belief seems to be withheld. I postulate and discuss nonrational influences producing resistance to belief, including the fear of being in error, the fear of rejection from the scientific community, irrational requirements of logicality, avoidance of consequences, and paradigm fixation. I also discuss issues in philosophy of science and epistemology in regard to proof.
\end{abstract}

KEY WORDS: belief; defense mechanisms; epistemology; William James; neardeath experience; resistance; scientific proof.

A curious incident recently occurred during an on-line discussion of survival of consciousness after physical death. The discussion was among a dozen or so professionals, including researchers and experts on near-death experiences (NDEs), psi, multiple personality, transpersonal and humanistic psychology, exceptional human experiences, philosophy of consciousness, and reincarnation research.

In brief, what happened was that an exceptional NDE case was presented in which the experiencer reported accurate external perceptions during the initial phases of the NDE when the body and brain were medically monitored and the brain was physiologically inert. The puzzle was not the case itself, but that after it was presented on-line, there were no comments, critical or otherwise, by any of the discussants.

Arthur Hastings, Ph.D., is Professor and Director of the William James Center for Consciousness Studies at the Institute for Transpersonal Psychology. Reprint requests should be addressed to Dr. Hastings at the Institute of Transpersonal Psychology, 744 San Antonio Road, Palo Alto, CA 94303; e-mail: ahastings@itp.edu. 
This remarkable case appeared to be ignored completely by these motivated, knowledgeable researchers and clinicians. The curious situation was like the A. Conan Doyle story of the detective Sherlock Holmes (1892). Holmes was investigating the stealing of Silver Blaze, a champion horse, and called the attention of the Scotland Yard inspector "to the curious incident of the dog in the night-time." The inspector was puzzled. "The dog did nothing in the night-time," he said. "That was the curious incident," explained Holmes, and this led him to suspect the horse was taken by someone familiar to the dog. Similarly, it is curious that the members of this prestigious group, myself included, said nothing when we heard about this case.

This exceptional case is an out-of-body experience (OBE) that happened during the NDE experience of a woman referred to as Pam Reynolds. It was described by Michael Sabom in his recent book Light and Death (1998). The experience occurred during highly sophisticated surgery for a brain aneurysm. The eyes of the patient were taped shut. The ears were plugged, but with transducers that provided stimulus sounds to check the responsiveness of the brain. The blood was circulated through an external heart-lung machine. The temperature of the body was then cooled to $58^{\circ} \mathrm{F}$, the head of the table tilted up, and the blood drained from the brain. There was no detectable electrical activity in the brain, and it was unresponsive to the sound stimulation. In this condition the aneurysm deflated and was safely repaired.

After the surgery, the patient reported having an NDE during the procedure. The report of the OBE perception by the patient described the specialized surgical instruments, conversations in the operating room, and other events that were confirmed to have occurred when she was anesthetized and unresponsive, with her eyes and ears sealed. The NDE visions presented a full experience that corresponded to reports of other NDEs: a sense of movement to an otherworldly place, life review, and meetings with nonphysical beings.

After the conferees read the case, there were no comments, either criticizing the case or hailing its features. After three months had elapsed, conference moderator Charles Tart posed the question of why there had been so little response to the Reynolds case. He wrote that the experience gave "really hard data that at least part of an OBE/NDE occurred in a state where monitored brain functions show the brain was not functioning at any but the most primitive levels, and then the NDE probably continued on when there was no blood in Pam's brain." I would like to comment on this lack of response, which turned my thoughts to how 
we decide to believe or not believe something. This question is particularly worth considering when the conclusions from this case (and some other issues in science) could be far reaching for human potential and meaning, both intellectual and emotional.

\section{William James's "The Will to Believe"}

I recently read William James's 1896 essay "The Will To Believe," one of his better known short writings, given first as a lecture for the philosophy clubs at Yale and Brown Universities. James said the talk was a "justification of faith, a defense of our right to adopt a believing attitude ... in spite of the fact that our merely logical intellect may not have been coerced" (James, 2000/1896, p. 198). His proposal is that sometimes one is justified in believing, through there may not be perfect logical, evidential, non-controvertible proof for the conclusion. We are not only justified in believing, but perhaps called to do so, by our passional self in contrast to our rational self. We cannot always wait for sensible (complete evidential) proof, he said. James carefully addressed the positions that everything should be scientifically or logically established before belief is justified. Objective evidence and certitude are doubtless fine ideals to play with, he wrote, "but where on this moonlit and dream-visited planet are they to be found?" (p. 207). Thus, where there is a genuine option that cannot be decided on intellectual grounds, he asserted that we lawfully may and must decide from our feelings and heart, leading us to "will to believe."

So the question was even more puzzling as to why, with all the evidence before us, evidence that empirically stood against the theory that NDEs are hallucinations of the brain, evidence that prima facie implied that there was consciousness and personal awareness in the absence of brain function, and when there were reports of some form of perceptions of external material reality with sensory organs physically blocked and probably neurologically nonfunctional, and other avenues of alternative explanations blocked, given all this, why was there so little acceptance of the conclusion at least that consciousness and perception were not, in this case, dependent on the brain and sensory organs? To go slightly further, if this was true in this case, could the hypothesis be extended as generally true for human beings?

Perhaps the others in the discussion really accepted that the conclusion was reasonably established, but simply did not write, "Well, that settles that issue, now what is the next step?" If they believed this, 
they did not bother to say so, even though this would be a conclusion of great importance. Or perhaps they disagreed with the evidence or the implied conclusion. If so, there was no critical challenge to the evidence, nor refutation of the logic, and in my experience my friends are not the silent type where such matters are concerned. Rather there was the sense, even on the neutral typeface of e-mail, of a feeling of avoidance.

In thinking about this, I was struck by the idea that there may also be the will not to believe, or perhaps more descriptively, the resistance to belief. It seemed to me that there are forces in ourselves and in society to prevent belief on certain kinds of conclusions. Once this was hypothesized, it was not difficult for me to do some self reflection and find these pressures in myself, and to observe them in others, in the media, and in science itself, even though one of the principles avowed in scientific theory is to be neutral and let the evidence speak for itself.

I am using the term "belief" similarly to James, who seemed to treat it as a hypothesis, a conclusion, a statement about the nature of reality. He used terms such as these: a believing attitude, an intellectual opinion, faith, a proposition, and truth. Dictionary definitions refer to belief as an acceptance of some statement as "true," which in turn means existence or correspondence to reality. It seems to me that James was also pointing to the emotional and passionate dimension of belief, a sense of acceptance, a letting it into the self. Passion in the time of James referred to strong or commanding emotions, and there were concepts of a "passional self" in contrast to a "rational self." Today we might use terms such as intuition, emotion, or felt sense.

James was speaking against those who withhold belief unless the conclusion is irrefutable. He did not mean that one should believe simply on the basis of emotional preference, but rather, if there is reasonable evidence to support an option, or a choice of equal options, even though no absolute proof, then one is justified in choosing to believe the conclusion. What I am exploring here is how such reasonable (and even likely) beliefs may be restricted, and even excluded, by nonlogical, and often unnoticed attitudes. On the other hand I am not advocating that beliefs in hypotheses should be unconditionally given regardless of lack of evidence. I am addressing cases in which there is plausible, sometimes sufficient, evidence. Acknowledgment must also be given that there can be ambiguity in what is to be considered reasonable evidence.

James was not advocating that we should believe something just because it feels right to us. He was not asserting that we have a right to believe because the conclusion is emotionally satisfying. My colleague 
Rosemarie Anderson remarked once about the tendency of some researchers to take a personal experience and turn it into a cosmic principle. This is similar to James's comment that a transcendent experience can be totally persuasive for the individual who has it, and that it solidifies any associated intellectual content into beliefs (James, 1958/1902, p. 496). But, he further commented that such a feeling of truth does not make it a duty for others to accept the beliefs uncritically.

The situations of concern here are ones in which data are available as evidence, where there are good reasons for conclusions. These are the situations in which James said we can call on our passion to move us forward. This paper examines nonlogical reasons that prevent even a reasonable movement forward.

There are ways of accepting a possible conclusion as real, dropping one's distance, and acting in accordance emotionally and intellectually, yet still being able to relinquish the position if further evidence shows otherwise. Some people may do this by holding "working hypotheses," others through flexibility of commitment to views, or by compartmentalizing in a positive way without rejection. Others may be passionate advocates for a belief, yet able to relinquish it without prejudice when the evidence so indicates.

\section{Nonrational Forces Against Belief}

My proposition is this: that there are nonlogical pressures as well as logical pressures on us as thinking beings to avoid belief and to back off from commitment; that these often come from fear; and that they have little to do with scientific or logical reasons. These may turn into the determination not to believe. They are often productive of ego defense mechanisms, such as rationalization, projection, and dissociation. This paper will present some of these nonrational pressures to withhold belief, and also acknowledge that there can be valid logical reasons not to believe, these latter having gotten most of the attention in science and research.

\section{Fear of Being in Error}

To begin with, the resistance to belief can come from the fear of being wrong, of accepting a conclusion that will prove to be in error, the fear of being mistaken and proved incorrect. It is a preventative, defensive strike. As James described this, it is the assumption that it is "better to risk loss of truth than chance of error" (James, 2000/1896, p. 215). I can 
imagine that this principle may be very important in some areas such a medicine or rocket science, but it is easy to extend it too absolutely. The fear of being wrong, even in private beliefs, can be emotionally threatening for those in scientific or research fields, where self identity and self concept may be based on the ability to be credible and trustworthy in certifying knowledge.

\section{Rejection from the Scientific Community and Colleagues}

Asserting a belief that might be proved wrong or appears to be in error can lead to social rejection and exclusion from the scientific community. In believing something that is against the prevailing accepted position one risks of being humiliated, embarrassed, labeled unscientific or emotionally biased, and excluded from the fellowship. Attaining and maintaining social integration is a powerful motivation for scientists as it is for anyone else. Connection with others and loyalty to each other mean identity and survival, and to deviate is risky and threatens the loss of one's place in society. To reinforce this fear there are ample examples of those who have believed erroneously and suffered humiliation and loss of credibility. Unfortunately there are examples of those who believed correctly, but in conflict with accepted views, and who also suffered.

A medical example is the observation that high levels of homocysteine can lead to ateriosclerosis, developed by Kilmer McCully in the late 1960s. This theory stood against the prevailing idea that cholesterol and dietary fats were the main contributors to cardiovascular disease. Other researchers called the homocysteine theory a hoax and crazy. McCully's laboratory at Harvard Medical School was physically moved from his department to a basement and deprived of key personnel. $\mathrm{He}$ was unable to renew his grants under these conditions and was forced to leave. For more than two years he was unable to find another position to continue his research. The importance of homocysteine in heart disease is now supported by substantial evidence from thousands of research studies. The theory leads to effective preventive therapies with $B$ vitamins. The biomedical research on this is clarifying the mechanisms of several other diseases as well (McCully, 2001).

\section{The Need to Be Rational}

The fear of being irrational is powerful. In this Western culture, which is strongly rationalist, the charge of being irrational is a damning one. 
This fear of irrationality can lead to an attempt to be totally logical, to believe only if the proposition is completely logically valid or has complete evidential proof. But, while logical equations $(2+3=5)$ are true by definition, there are no empirical conclusions (such as "All humans are mortal") that can be absolutely proved. This means that there cannot be total objective proof, and there will always be an inductive gap, a lack of complete logical connection, an assumption that is not provable. James spoke to this in his essay, writing that absolute truth was wonderful, but inquiring rhetorically as to where it could be found. The mathematician Kurt Gödel demonstrated that there are always assumptions in any closed system (theory) that cannot be proved or disproved. Furthermore, any open system can not be complete, so there you are.

Sometimes holding this absolute requirement to be logical is rationalized as being scientific. If this is a defense to avoid commitment to conclusions one does not wish to accept, it is a pretty safe position. As William James said, certitude will not come, even for propositions that appear to be empirically strong.

An implication of this logical gap is that every belief stating an empirical conclusion will contain at least one unproved assumption in its evidence or proof. If this is so, then every scientific conclusion is being believed on less than complete logical proof, and as James might have said, on the basis of the passion or will to believe. The highest threshold for proof appears to be invoked more frequently for propositions that run against prevailing ideas, themes, and paradigms, and ignored for conclusions that are consistent with prevailing ideas, themes, and paradigms.

\section{Is Objective Validation Possible?}

It appears that the Reynolds case meets many criteria that NDE researchers have been longing for. Many researchers have wished for a case where the brain waves were definitely flat, as proof that the experience is not dependent on the brain. Now that such a case is here, what does it demonstrate? For example, does it prove the objective reality of the otherworldly realm? Not directly: in the physical world, there is no objective verification of the reality of the NDE domain as a self-existing, nonphysical realm. There cannot be. For example, if we hear barking, we can infer that there is a dog somewhere, because we have verified that there are dogs. The dog is in the same physical world as we are, and therefore we can establish the underlying generalization that barking 
usually comes from dogs. Further, I can go out into the street and see for myself, and others can do so also. This is the predictive function of the argument. Barring group hallucination we usually accept this mode of consensual validation and consider it objective.

Such observational verification is not possible with NDEs (and channeled beings, ESP, and black holes, for that matter) because we have no independent, direct verification that such things exist, so we do not know what kind of evidence will be indicative of their presence. Technically, this involves a circular argument. The argument is sign reasoning (from effect to cause), but there is no evidence on which to base the generalization that gets us from the evidence to the conclusion. As for the persuasive feel of the subjective experience, there is the alternative explanation of fantasy. As hypnosis demonstrates, perceptions, inner and outer, can be manufactured by the mind. We need more sophisticated ways of approaching the complex inferences involved in these cases, beyond the rational thinking of conventional methods.

\section{Avoidance of Wishful Thinking}

A further reason for commitment phobia is a fear of being tarred by one's own inner critic or one's outer colleagues with the dirty brush of wishful thinking, enthusiasm, and emotional beliefs. Objectivity is rightly an important scientific stance. If a researcher has too much desire for a particular outcome, this can lead to biased research, uncritical thinking, and even fraud. The literature of science is filled with reports of false ideas, conclusions, delusions, and pathology of belief. Sometimes this is inadvertent, but at other times the scientist has apparently reasoned, "I know it's true, so I'll select those data that show it most clearly." Sometimes the research design or conduct is arranged (consciously or not) to produce the expected answers. (A desire to continue to receive funding may play a part in such nonlogical influences.) I do not condone such personal overriding of integrity. However, passion is also an important and necessary scientific quality. In actual fact, many fine scholars and researchers have demonstrated that one can have hope and enthusiasm for the likelihood of a particular outcome, and yet hold to strict evidence and criteria, and be willing to criticize the case if the evidence is not there.

In his book, Old Souls: The Scientific Evidence for Past Lives, Tom Shroder (2001) recounted how he accompanied researcher Ian Stevenson in interviews in Lebanon, India, and the United States with families of children who appear to remember a past life. Many of Stevenson's 
cases have documented the verification of a child's detailed memories and behavior, and convincingly eliminated alternative explanations, so that it takes effort and determination for critics to reject the suggestion of reincarnation (Stevenson, 1980, 2000). Nevertheless, time after time in the book Schroder noted how Stevenson was honest about the quality of the evidence, and meticulous in noting specific objective weaknesses in specific cases, even though he was persuaded of the general conclusion based on the accumulation of cases.

A charge is sometimes made that NDE researchers and psi researchers are guilty of wishful thinking, for example that they are trying to prove God, or advocate religion. One might see the ego defense strategy of projection operating here.

\section{Scientific Method as a Basis for Knowledge}

The principle might be asserted in scientific writing and training that a true researcher, scientist, or psychologist, should accept only conclusions that can be established, and unless something is grounded in evidence (according to the correct method) then it should not be believed. This prescription must surely be violated more than we would like to believe, given that very little can be established unequivocally in a strict sense. This is one reason why the post modern critics and deconstructionists can be so successful in taking apart knowledge, social beliefs, and institutions.

In philosophy of science, this principle ranks up there with the Golden Rule, and it might be said to be the central pillar of science: knowledge is to be based on data that meet criteria of evidence, and proceeds through lines of reasoning, excluding alternatives, to conclusions. Within any such process, there are likely to be unnoticed assumptions and hidden variables that constrain and influence the conclusions. Thus, it seems to me that a case can be made for situations that are exceptions to this principle. One should know when to question facts, when to use insight, and when to be able to leap to conclusions by way of limited stepping stones.

This is not to disparage the scientific method, but to note that it is a method, not truth itself. Any method has its weaknesses, blind sides, and limitations, and it does not always accomplish its goals. As an obvious example, the recent rise of qualitative methods in personal sciences, that is, methods that gather data of experienced reality, have opened up the knowledge of values, meaning, and inner experiences to investigation. This produces conclusions in a different mode from 
the empirical data of quantitative experiments and statistical analysis. These conclusions show the feel of an experience, the inner structures and themes, motivations, phenomenological elements, the felt realities of paradigms, meanings, and perceptions. These qualitative approaches may not be accepted by investigators used to behavioral and statistical findings.

The qualitative realities of subjective experience and meaning did not come into acceptance easily in science, though everyday people lived them all the time. Ordinary dreaming as a reality was rejected more or less because it was subjective, and it was ignored in psychology and physiology until rapid eye movement monitoring established it as an identifiable genuine brain state. Lucid dreaming refers to the state of being asleep and dreaming while being fully conscious that you are dreaming (LaBerge, 1985). Dream researchers and psychologists for decades viewed it with skepticism. The few anecdotal cases and reports in occult literature were ignored.

In the late 1970s Stephen LaBerge developed an ingenious method of confirming lucidity within dreams, by moving his eyes while still in the dream state to signal his consciousness. When a research report on this work was submitted to the journal Science, one referee gave it his highest recommendation, while a second wrote that he found it "impossibly '... difficult to imagine'" (LaBerge, 1985, p. 66). The editor accepted the second reviewer's judgment. A second submission to Science with twice as many subjects and attention to the reviewer's objections was also rejected. The report was submitted to Nature and returned without review as being "not of sufficient general interest" (LaBerge, 1985, p. 66).

In a stance similar to dismissing lucid dreaming as a fiction, Norman Malcolm, a well-regarded American philosopher, wrote an essay that logically questioned whether dreaming could even exist (Malcolm, 1959). Transpersonal psychologist and dream researcher Tart commented that after he read the essay he was so disturbed that he had nightmares all night (Tart, 1969).

The acceptance of lucid dreaming suggests an important principle. For belief to be accepted in a physicalistic scientific arena, the inner experience has to have physicalistic effects. This is in accordance with William James' position that to be real, something has to have an effect. In this case, it has to affect something that we already believe to be real. Another case in point is hypnotism, which languished for many years as suspiciously subjective and nontheoretical. Ernest Hilgard's research on hypnosis at Stanford University was made acceptable, in his opinion, because measures of the hypnotic condition were developed 
that met criteria of standard instruments, such as reliability, consistency, and prediction of hypnotic effects, all of which are in the empirical realm (Hilgard, 1971). He also pointed to the change in the climate of behaviorism, which was becoming less strident and more open to direct interest in subjective phenomena. Hilgard was once asked how he was able to make hypnosis research respectable, and he replied that it was because he developed scales to measure it (Ernest Moore, personal communication, 1987).

\section{Avoidance of Dissonance}

Another influence may be both logical and nonlogical in affecting belief. If a person accepts a statement of belief, then it needs to be treated as true, with all its consequences. One expects oneself to think and act in correspondence with the belief. This is a pressure toward consistency and avoidance of dissonance, a powerful force that can create resistance, particularly in controversial, ontological issues of reality. With NDE cases, for example, willingness to believe the evidence of such cases appears to lead to many further beliefs relating to nonphysical perception, consciousness, and brain states, other kinds of reality, survival of death, and levels of the personality. If one or more of these implications are beliefs the person wishes to avoid, then the whole case may be rejected to relieve the dissonance. This rejection of data or conclusions can be a kind of dissociation or compartmentalization, in which any dissonant information is separated cognitively from contact with the rest of the belief system.

From the standpoint of scientific thinking, one of the reasonable tests of a fact or theory is how it fits with current thinking, such as being consistent, filling in a gap, or furthering the explanatory power of a theory. For this reason a case can be made for caution toward claims that are anomalous to current thinking (Bauer, 2001). Without denying the value of such a process, it can be said that consistency can also illogically operate to reject and dismiss innovative concepts and new information.

\section{A Thought Experiment}

As a thought experiment, I invite you to imagine that you believe that the Reynolds case is valid and that it provides sufficient evidence for the elements it contains-personal consciousness can be independent of the brain, external reality can be apprehended without the physical 
sense organs, the Light is real and self-existent, and so on. You can select and state the beliefs in your own way, which might be different from my formulation, or that of anyone else. Then consider how these beliefs, taken seriously, would change your personal belief structure, your world view, your life values, and self identity.

Next, reflect on how the acceptance of the propositions as true would affect your professional work. If you are a therapist, how would it change your counseling and psychotherapeutic approach? How would you counsel a bereaved person, a suicidal person, or NDEr?

If you are a researcher, consider what research projects you would propose. If you are more theoretically and philosophically inclined, what would be your conceptual questions? In terms of the delicacies of academic politics, what would be the challenges of "coming out" in academia? How would you talk with your nonbelieving colleagues?

Some investigators, philosophers, and scholars have already committed themselves to a definite belief in the existence of various unconventional realities. Others vigorously denounce those who believe in such things as unscientific, biased, soft-headed, and, in general, wrong. There are also those who reserve judgment by concluding that NDEs are interesting, that they contain suggestive evidence, and that the subject needs more research, preferably with a more conclusive case. I have never been comfortable myself or as a professional researcher with either the fanatical true believer or the fanatical skeptic, even when I agree with their point of view.

\section{Resistance to Belief in Other Fields of Science}

I have also observed this fear-to-believe tendency in parapsychological circles, in which for several years various of my colleagues have said that we ought to accept the reality of psi and get on to figuring out what makes it tick and how it functions for individuals and society. I think this is actually beginning to happen, but it took root slowly, and a considerable number of psi researchers still will not take a stand on the question, though the evidence is more than ample, and meta-analyses confirm replicability and consistency. Perhaps a reason for this is the lack of a satisfactory theory, which I will discuss below. A well-known phenomenon is for a dedicated psi researcher to have a personal experience with a parapsychological event and then to find himself or herself figuring out ways to discount it or even forget it.

In reincarnation research, such investigators as Stevenson, Antonia Mills, Erlendur Haraldsson, Jürgen Keil, Satwant Pasricha, and others have compiled and documented more than enough evidence to establish 
by any reasonable standards the reality of reincarnation memories. Although reincarnation is held in many cultures as a popular belief, it has made only a little headway in science, clinical psychology, biology, medicine, and philosophical inquiry. The reason is not hard to grasp. I mentioned lucid dreaming above as another area in which the reality of the experience was initially denied even in the face of careful research methodology. Some other areas where this belief/resistance to belief dialectic arises include transpersonal psychology, subtle energies, exceptional human experiences, consciousness, and altered states of consciousness. These are all nontraditional areas of research, very different from the natural sciences.

There are paradigm clashes, disputed "facts," and controversial theories in the natural and social sciences as well, and nonrational resistance to belief has held sway there also, as evidenced by the recent vicissitudes of tectonic plate theory, ball lightning, regeneration of brain cells, and pre-Columbian settlement of the Americas. Compared to the discussion of pseudoscience, pathological science, and self deception, the natural science literature on resistance to belief is small. Molecular biologist Gunther Stent (1972) discussed the resistance to discoveries such as Gregor Mendel's genetic theory and Michael Polanyi's theory of gas adsorption on solids, both backed by empirical evidence. His suggestion was that these ideas were premature. At the time of their emergence, their implications could not "be connected by a series of simple logical steps to canonical, or generally accepted, knowledge" (p. 84).

Is this a rational or nonrational criterion? It is rational regarding the criterion of consistency with consensus as mentioned earlier, but this criterion has limited scope in that theories may be incorrect, or inadequate. In cases where there is no alternative theory to explain the apparent facts, as with Mendel's pea breeding, the tendency of holders of the consensus is to ignore them, as Thomas Kuhn (1970) pointed out in his discussion of how paradigms shift. Stent applied this necessity for a theory to research on extrasensory perception (ESP) and commented, "in the absence of a hypothesis of how ESP could work it is not possible to decide whether any set of relevant observations can be accounted for only by ESP to the exclusion of alternative explanations" (p. 88).

This has been a frequent criticism of research on psi. I would guess that all parapsychologists agree that a theory is desirable, and most are in agreement that no acceptable one exists. This, however, has not halted the research and accumulation of data on the phenomena, and the elimination of alternative hypotheses, such as subliminal perception, electromagnetic energy, fraud, statistical probabilities, and problems of research design. The data of psi remain, bereft of a theory 
to explain their occurrence. What suggests itself to many is the possibility of other paradigms, with radical differences from the present one, and which support an explanation of psi phenomena.

James would have considered the observations of genetic transmission and psi to be part of the "unclassified residuum" (Murphy and Ballou, 1969, p. 25). "Round about the accredited and orderly facts of every science," he wrote, "there ever floats a sort of dust-cloud of exceptional observations, of occurrences minute and irregular and seldom met with, which it always proves more easy to ignore than to attend to. The ideal is that of a closed and completed system of truth" (James, cited in Murphy and Ballou, 1969, pp. 25-26). James wrote that once the system of truth is in place, any alternative is no longer imaginable and phenomena that the system can not classify are believed to be untrue. To renovate the science, he said, "look steadily after the irregular phenomena" (cited in Murphy and Ballou, 1969, p. 26).

Established scientific conceptions were identified also by sociologist Bernard Barber (1961) as a force in resistance. Besides the example of Mendel's gene model, Barber mentioned the Copernican solar system model, resisted by the predominant astronomer Tycho Brahe, and the resistance to Louis Pasteur's biological model of fermentation and Joseph Lister's germ theory of disease, by scientists whose preconceptions were for a chemical explanation. Another social force in scientific culture according to Barber is the adherence to specific methods and models. He noted that there have been subcultures in science favoring particular approaches, such as mathematical modeling, and rejecting theories that cannot be put in such forms. Theories of electromagnetism were resisted by some scientists in the 19th century, he wrote, who did not see how they would fit into Newtonian mechanics. Barber discussed other influential social and cultural forces, including religion, reactions to the professional status of the researcher, the resistance of specializations to outsiders making discoveries, rivalries of scientific societies and schools of thought, and resistance by senior scientists to new ideas. These are nonlogical cultural and social forces along with the more individually based motivations that this present paper discusses.

\section{Paradigm Fixation}

It is evident from the discussion of the inertial force of established scientific ideas and preconceptions that there is a field of influence from the scientific paradigm or worldview that is accorded consensual reality 
in the scientific community. The paradigm is the set of accepted theories, beliefs, data, and assumptions held as a valid description of reality and the ways of researching it (Kuhn, 1970). A paradigm may exist on a broad scale, as with quantum mechanics, or on a narrow scale, as with the germ theory of disease. If a potential belief is at odds with the prevailing paradigm, and one identifies with the paradigm professionally or personally, resistance arises to the belief.

An example is the theory of continental drift in geology. Visually the shape of the eastern edge of the Americas can be seen to fit the western line of Europe and Africa. Is this a coincidence? Alfred Wegener proposed in 1912 that the continents had once been together as one land mass. Besides the "fit," other evidence included flora and fauna common to now separate continents. This idea was rejected by earth scientists, apparently because the then current paradigm held that the land masses did not move, but were fixed on the crust. In the 1960s when the field of paleomagnetism was developed, and the mid-Atlantic spread identified, the tide turned, and the continental drift model became accepted. This topic may be an example of how paradigms can be believed as working models, yet still be open to change, because currently the tectonic model is being challenged by additional data (Pratt, 2000; Smoot, 2001).

We might call this resistance to belief a paradigm fixation, in which there is an investment in the set of beliefs of the paradigm, that is, the data, conclusions, conceptions, and methods. For example, the assumptions, data, and treatment approaches are very different for traditional Chinese medicine and Western medicine. The paradigm for each is embedded in a context of culture and community. These and the paradigm are mutually reinforcing. The paradigm may include metaphysical assumptions, such as materialism, idealism, animism, and other realities. Identification with the paradigm entails accepting the assumptions. This can be a consensus of the scientific community, and it can also be an aspect of personal identification for an individual. The same fixation may occur with favored theories or lines of research within a science. Leaders in the field, as with Barber's societies and seniority, may take stands supporting an accepted line of research, and may influence social rewards such as publications, network connections, and funding for researchers.

Logically a paradigm is a hypothesis, and should be held so long as it seems to explain and predict, and revised or released when it no longer corresponds to the data. However, paradigms seem to have a life of their own, once they resolve a confused situation in a comprehensive 
enough way. It is as though they are cathected, in the Freudian sense, by the scientific collective, and defense mechanisms arise to protect them. Belief in them can have strong emotional mass, which ignores incongruent facts and conclusions, explains away problems, and repels competing ideas like opposite magnetic poles.

The theory of relativity is an example in physical science. In physics, the results of the well-known Michaelson-Morley experiment in 1887, designed to measure ether drift, presumably found that the speed of light did not change whether it traveled in the direction of the moving earth or against the direction of the moving earth-thus showing no effect of an ether. This was interpreted in relativity theory to mean that the speed of light was a constant no matter what the context. This theory was at first resisted, and then received widespread acceptance. However, there are six other experiments in the literature following the first one. All but one contradicted the original Michaelson-Morley research, and in fact some have argued that ether drift was shown in the original research, although not at the rate predicted (Munera, 1998). The paradigm of relativity incorporated the first result.

Another example from relativity theory was the expedition to Antarctica to measure the deflection of the sun's light during a solar eclipse, which presumably validated the relativity paradigm further. Recent critiques have suggested that the measurements reported were selective and not adequately carried out (McCausland, 1999). Many mainstream physics journals are said to reject, without review, articles critical of relativity theory (McCausland, 1999, p. 288). Could this be because there is a nonlogical assumption that the theory is the truth, and any criticism therefore can be ignored? In these cases one does not need to believe that Albert Michelson and Edward Morley, or the Antarctic group, were incorrect; but rather I wish to point out only that there appear to be nonrational forces preventing investigation of reasonable alternative data and conclusions because the theory of relativity has been accepted.

Spokespersons from science do not often reveal their adherence to the doctrinal values embedded in the paradigm, but this attitude surfaced in critical comments elicited by a recent newspaper report (Yeung, 2002). The paper reported the research carried out by on distant healing in a population with acquired immune deficiency syndrome (AIDS) (Sicher, Targ, Moore, and Smith, 1998). The distant healing was carried out by ten healers of a variety of persuasions, including Christian, nonreligious, and shamanic. The treatment, carried out in an accepted double blind random design, had positive effects on mental and physical 
health measures. One critic, a physician, was quoted as saying, "Medicine and science, in the last 500 years, has tried to eliminate concepts of the spiritual, of religion and belief, which offer nothing toward the advancement of science... What they are studying is impossible" (Yeung, 2002 , p. 22-23). An academic psychologist was quoted with this comment: "It's not based on any scientific model, therefore any results that come from it are suspicious because they don't make sense in terms of the gradual accumulation of science" (p. 23). However, this latter speaker also said that he thought this field was worth studying, because "sometimes investigation of far-fetched ideas does produce important results and new knowledge" (p. 23).

\section{Metaphysical Assumptions}

When a paradigm has metaphysical assumptions (axioms, in theory language), then belief is likely to be withheld from ideas and data that are inconsistent with these assumptions. The medieval belief that the planets and stars orbited the earth could be considered a paradigm that fit the moral and doctrinal view of the church that the earth was the special creation of God. Opposing beliefs were rejected. I have focused in this essay on the contemporary Western scientific community. In this contemporary worldview, the influence of metaphysical directives such as logical positivism, empiricism, reductionism, repeatability, mechanism, predictability, and exclusive materialism have created a paradigm that has strongly dominated Western science and technology. These ideas have provided very productive physical sciences, and advances in human well-being, but they have also imposed limits to what is considered real, what is considered evidence, and what kinds of hypotheses are allowed about objects, people, consciousness, and the cosmos. This metaphysical conflict is one of the reasons that assertions about consciousness, near-death experiences, reincarnation, transcendent experiences, ESP, pre- and perinatal awareness, angels, God, lucid dreams, meridians, subtle energies, other realities, shamanic worlds, UFO encounters, and other reports with varying degrees of plausible evidence have had difficulty getting any attention other than criticism and rejection from many who hold the current scientistic position. The paradigm considers unreal any phenomena and epistemology that do not conform to the metaphysical qualities listed above. Sometime this is a reasoned disbelief, with a rationale that something that is not physical simply is not real. Such a view holds that the possibility of a nonphysical 
world in an NDE is not real. If the experience is to be explained, the explanation must come from known or unknown physical sources. Stated this plainly, it is evident that the position is based on circular reasoning, since "real" simply means physical, and that is precisely the assumption being questioned.

The proper scientific answer to a new belief is to challenge the proponent of the belief to "prove it." However, if the proof is expected to be in terms of empirical materialism, reductionism, mechanism, and physical data conforming to the terms of the current paradigm, then that cannot be done for many of these subjects-any more than attempting to prove that light is a wave, if the paradigm and its instruments of measurement are set to measure particles; or attempting to prove that the earth goes around the sun, when the criterion is what everyone can see with his or her own eyes. On the other hand, we have no other accepted kinds of data to use as proof or other ways of knowing. For that reason, the few inroads of acceptance into these areas have been when a nonparadigmatic experience has been matched with a well-accepted part of the paradigm. The use of electroencephalography to confirm the consciousness state of lucid dreaming, and to validate meditation depth are examples. Another instance is the use of physiological measures to demonstrate that a meditation state lowers blood pressure.

In NDE research, the initial stage of leaving the body (an OBE) often involves perception of the physical location, such as an operating room or an accident scene. These perceptions can be verified, and thus can provide an external confirmation of the subjective OBE report. If it is assumed that the continuation of the NDE perception is just as valid as the OBE perception, then the implication is that the further visionary settings have some kind of independent reality that acts as a stimulus for the perception. However, there is no way of knowing at present whether the assumption of continuity is justified. Such are the problems of these new areas of inquiry. It may be necessary to come at these issues of validation, inference, and proof from a set of different assumptions and methodologies. I do not see this as a problem, but rather an exciting and stimulating exploration.

\section{Critical Thinking and Research}

To return to the Reynolds case, suppose we draw these conclusions: (1) that this case is sufficient to demonstrate that there is conscious 
experience when the brain is not functioning (it does this by eliminating the other alternative explanations, such as hallucinations from an active brain); and (2) it demonstrates adequately that there can be detailed auditory-like and visual-like perception without the functioning of eyes and ears.

In suggesting such conclusions, I do not wish to say that the Reynolds case cannot be critiqued. It deserves thoughtful and critical analysis. Gaps in the data or analysis may be found that raise questions of evidence and inferences. Of course, such questioning is appropriate for any evidence, and there are many incidents of models and data that fade away under scrutiny. I am not advocating belief in conclusions without thoughtful consideration. Nor am I asserting that areas of inquiry such as NDEs and psi should be treated as Truth. Regardless of their validity, the reactions to them provide striking illustrations of the power of nonlogical influences on presumed scientific investigation. I am simply applying these ideas to situations where there is evidence for drawing a conclusion with a reasonable degree of probability, and particularly to situations that are at variance with the prevailing scientific or cultural view.

The topic of hallucinations brings up another subtle nonrational influence, which I will mention briefly. Some writers and researchers have labeled OBEs and NDEs as hallucinations, and similarly in the psychiatric bereavement literature, the apparitions of deceased spouses are usually referred to as hallucinations. But to call something a hallucination does not explain it. It merely offers a name that we are familiar with and causes us to lump a diversity of experiences into one dismissive category. So far as I know, there is no adequate theory of hallucinations that is grounded in brain neurology. Thus to call an apparition a hallucination, meaning that it is a fantasy, is implicitly presuming an explanation that dismisses and pathologizes it, neither of which is necessarily supported by the evidence.

Suppose the Reynolds case, and others of similar quality, were to be accepted as proving what they appear to prove. If subsequent information, facts, and experiences cast doubt on the above conclusions, then the conclusions should be appropriately shifted. But until then, suppose that investigators were to accept that they are true as working hypotheses and act and believe accordingly. If those conclusions were seriously accepted as valid, I ask these questions: Where do we go from there? What do they imply? How do we further explore the facts of the situation and create models to map them? What effect does this conclusion have on our worldviews and belief systems? 
An NDE case does not necessarily establish that the prima facie content of the experience, such as tunnels and beings of light, are really "over there" in another dimension. Maybe they are, and maybe not. If there is more to reality than we know, certainly our language and habitual ways of thinking are not familiar with those reaches, and we may misperceive and fumble in our understanding in many ways. We also know that there are many mansions in the realm of the human mind, to modify a phrase. There may be sophisticated and complex symbolism, subtle structures, cultural influences, and forms of consciousness that are producing these phenomena, which are experienced in whatever reality they possess.

\section{How Do We Know? Epistemological Issues}

It is necessary, therefore, to look more deeply at the otherworldly part of the NDE. Here again, some will believe that this part of the experience is a reflection of self-existent realities, others will resist belief and assert that it is wish-fulfilling, culturally-driven fantasies; and others will say it is interesting, at least has positive effects, and needs further research. The problematic epistemological aspect of this stage of theory and research is that we do not have the possibility of verification in this material reality of the perceptions reported, as we do for OBEs. The experience in our illustrative case took place, given the report, when the brain was not electrically active, so this appears to be evidence for consciousness outside of the physical brain. That the experience took place in a nonphysical reality that has independent existence in a nonmaterial (or perhaps subtle physical) state can not be established with the empirical methods we now use. It may be helpful to innovate and draw from new methods of data collection and inference, such as intuitive awareness, consensual experiences in nonphysical realms, altered states of consciousness training, visualization, and imagery methodology. Data may be obtained on epistemological influences from studies of psychodynamics and belief systems; exceptional human experiences; symbolism and mythology; crosscultural studies in spiritual, psychic, and nonordinary realities; meditation experiences; esoteric spiritual teachings and practices; hypnosis; shamanic work; and psychedelic substances. Given these many perspectives, it may be that a new logic of analysis will be necessary to make sense of what is happening.

It is informative to add qualitative methodologies to learn the experiential and subjective phenomena in these cases, using interview, 
narrative, phenomenology, heuristic, intuitive sensing, and qualitative resonance, and remaining open to others not yet known (Braud and Anderson, 1998). Investigation of these areas and with these methods certainly suggests kinds of realms, as well as other forms of consciousness, separated from our ordinary consciousness by the filmiest of screens, as James wrote (1958/19902). These realms are usually experienced in the context of some belief system, such as a religion, a metaphysical view, or a folk culture, and this shapes them, though how much and what underlies this shaping is not clearly delineated. With openness to whatever is given in experience-a Jamesian idea of "radical empiricism" (James, 1912), diligent reflection, and educated intuition-I believe we can identify some of the recurring elements in these nonordinary areas of experience, accept them as established enough for belief, and then explore the consequences of that acceptance. To return to the original question, I suspect that some of the lack of response in our discussion was because the Reynolds case eliminated too many of the alternatives that had been raised about NDEs, and to take the case seriously would challenge accepted beliefs, self identity, emotions, commitments, and scientific personas; raise fear; and present conclusions that would require deep shifts in our own beliefs. But I believe we can be open to such beliefs and still be thoughtful, be objective, have integrity, and arrive at a deeper knowledge of ourselves and reality.

\section{References}

Barber, B. (1961). Resistance by scientists to scientific discovery. Science, 134, $596-$ 602.

Bauer, H. H. (2001). Anomalies and surprises. Journal of Scientific Exploration, 14, 459463.

Braud, W., and Anderson, R. (1998). Transpersonal research methods for the social sciences: Honoring human experiences. Thousand Oaks, CA: Sage.

Doyle, A. C. (1892, December). Adventures of Sherlock Holmes. XIII. The adventure of Silver Blaze. Strand Magazine, 4, 645-660.

Hilgard, E. R. (1971). Hypnotic phenomena: The struggle for scientific acceptance. American Scientist, 59, 567-577.

James, W. (1912). Essays in radical empiricism. New York, NY: Longmans, Green.

James, W. (1958). Varieties of religious experience. New York, NY: New American Library. (Original work published 1902.)

James, W. (2000). The will to believe. In Pragmatism and other writings (pp. 198-218). New York, NY: Penguin Putnam. (Original work published 1896.)

Kuhn, T. (1970). The structure of scientific revolutions (2nd ed., enlarged). Chicago: University of Chicago Press.

LaBerge, S. (1985). Lucid dreaming: The power of being awake and aware in your dreams. Los Angeles, CA: Tarcher.

Malcolm, N. (1959). Dreaming. London, England: Routledge and Kegan Paul. 
McCausland, I. (1999). Anomalies in the history of relativity. Journal of Scientific Exploration, 13, 271-290.

McCully, K. (2001). The biomedical significance of homocysteine. Journal of Scientific Exploration, 15, 5-20.

Munera, H. (1998). Michaelson-Morley experiment revisited: Systematic errors, consistency among different experiments and compatibility with absolute space. Apeiron, 5(1-2), 37-54.

Murphy, G., and Ballou, R. O. (1969) William James on psychical research. New York, NY: Viking.

Pratt, D. (2000). Plate tectonics: A paradigm under threat. Journal of Scientific Exploration, 14, 307-352.

Sabom, M. (1998). Light and death: One doctor's fascinating account of near-death experiences. Grand Rapids, MI: Zondervan.

Shroder, T. (2001). Old souls: The scientific evidence for past lives. New York, NY: Simon and Schuster/Fireside.

Sicher, F., Targ, E., Moore, D., and Smith, H. S. (1998). A randomized double-blind study of the effect of distant healing in a population with advanced AIDS: Report of a small scale study. Western Journal of Medicine, 169, 356-363.

Smoot, N. C. (2001). Earth geodynamic hypotheses updated. Journal of Scientific Exploration, 15, 465-494.

Stent, G. (1972). Prematurity and uniqueness in scientific discovery. Scientific American, 227(6), 84-93.

Stevenson, I. (1980). Twenty cases suggestive of reincarnation (2nd ed.). Charlottesville, VA: University of Virginia Press.

Stevenson, I. (2000). Children who remember past lives: A question of reincarnation (rev. ed.). Jefferson, NC: McFarland.

Tart, C. T. (1969). Altered states of consciousness. New York, NY: Doubleday Anchor.

Yeung, B. (2002, Jan. 9-15). A test of faith. S. F. Weekly, 20(49), pp. 19-20, 22-23, and 25. 